\title{
A NOTE ON THE SEROLOGY OF SARCOSPORIDIOSIS AND TOXOPLASMOSIS
}

\author{
BY \\ F. I. AWAD AND R. LAINSON \\ From the Department of Medical Protozoology, London School of Hygiene and Tropical Medicine
}

(RECEIVED FOR PUBLICATION NOVEMBER 12, 1953)

Serological methods for the diagnosis of toxoplasmosis have received considerable attention since the first authentic report of a fatal infection in a human infant (Wolf, Cowen, and Paige, 1939). The complement fixation reaction (Warren and Sabin, 1942) and the dye test (Sabin and Feldman, 1948) are now recognized as the two best methods of detecting the disease. Serological studies in sarcosporidiosis have not, however, been given the same amount of attention, although this infection has a much longer history than that of toxoplasmosis. For example, organisms designated as sarcosporidial in nature were described in the laryngeal muscle cells of a human patient (Baraban and Saint Remy) as long ago as 1894. Similar aggregations have since been described in isolated human patients in the muscles of tongue, biceps, heart, etc., and these have usually been given the specific name of Sarcocystis lindemanni (Rivolta). The discovery that chronic toxoplasmic infections are often associated with the formation of "pseudocysts" containing large numbers of organisms not only in nervous tissue but in skeletal and heart muscle adds to the suspicion that some reported cases of sarcosporidiosis in man and animals might in fact be cases of toxoplasmosis. Different investigators give different dimensions for these organisms. "Sarcosporidial spores" described in human infections range from 8 to $9 \mu$ long (Baraban and Saint Remy, 1894) to $4.25 \mu$ long (Darling, 1909, 1919). While it seems unlikely that organisms regularly of the first dimensions are Toxoplasma, suspicion arises in the case of smaller organisms. The issue is complicated by the fact that in some of these reports the "septa" and enclosing membrane associated with the more typical sarcosporidial cysts could not be demonstrated. Kean and Grocott (1945) concluded that in the absence of inoculation and serological studies the absolute identification of these two parasites is impossible.
In October, 1951, Mühlpfordt used the Sabin Feldman dye test in an endeavour to differentiate between infections of Toxoplasma and Sarcocystiso "Miescher's tubes" (sarcosporidial cysts) re? covered from gullet muscles of sheep or goats were inoculated per os or intraperitoneally inte guinea-pigs, rats, and hamsters, and the serum of these animals was tested by the dye test againstr toxoplasms. In all cases, preliminary tests made before the inoculation with sarcosporidia proo duced negative results, but after the infection was allowed to establish itself the animals reacted posio tively, thus suggesting that antibodies reacting with the toxoplasms were produced by the sarco® sporidial infection. Tests were then carried ouf with the sera of 45 sheep. In $26.6 \%$ of the animals the dye test was positive using Toxo? plasma in the presence of detectable parasites; in the remaining animals the results of both parasito logical and serological examinations were negative? From this investigation Mühlpfordt concludef that sarcosporidiosis cannot be differentiated from toxoplasmosis by the dye test.

In view of this apparent non-specificity of the dye test and the difficulties in microscopical diag nosis, it was decided to investigate the possibilities of antigenic relationships between Sarcocystis and Toxoplasma as far as the dye test and the comple $N$ ment-fixation antibodies were concerned, and tọ attempt to find a way of differentiating the two diseases.

\section{Methods}

Microscopical Examination of Sheep Tissues fo눈 Evidence of Sarcocystis tenella Infection.-The sites selected for microscopical examination were the oesophagus, heart, and diaphragm muscles. The oesophagus was the primary site for the large and obvious cysts, while scrapings from the muscle of heart, diaphragm, and oesophagus were place $\vec{D}$ separately on slides in normal saline under $\operatorname{cover} \frac{O}{\sigma}$ slips and examined under the $2 / 3$ objective. In view of the obvious limitations of such methods the terms 
"undetectable" was used in preference to "negative" when parasites could not be found by these means.

The Complement-fixation Reaction for Toxoplasmosis.-The method used here was exactly that as devised by Warren and Sabin (1942) and as modified by Warren and Russ (1948). The test was already in regular use by one of us in problems of incidence in toxoplasmosis. The antigen was prepared from a chorio-allantoic membrane extract from developing chick embryos inoculated with suspension of Toxoplasma.

The Complement-fixation Reaction for Sarcosporidiosis.-This reaction, again, was in current use by one of us in studies on serological methods for the detection of sarcosporidial infections in sheep. The antigen was prepared in the following manner:

Sarcocysts (Balbiania) were removed, free of muscle, from the oesophagi of infected sheep, washed in normal saline, and ground with sterile carborundum. Enough normal saline was then added to give a $10 \%$ suspension. This was quickly frozen and thawed four times in the methylated spirits bath refrigerator and kept at $4^{\circ}$ C. for a minimum of 15 hours. The suspension was then centrifuged at 4,300 r.p.m. for two hours, the supernatant clear fluid removed, and normal saline containing $0.1 \%$ merthiolate added to give an ultimate concentration of merthiolate of 1 in 10,000. The extract was stored at $-70^{\circ}$ C. A control antigen was similarly prepared from sheep heart and diaphragm muscle which failed to show infection either in scrapings or sections stained with haematoxylin and eosin; in addition the complement fixation reaction was negative.

The Dye Test. - The Sabin-Feldman dye test was used as modified by Cathie and Dudgeon (1949).

\section{Investigation}

Experiment A : Complement-fixation Reaction for Toxoplasmosis.-Rhesus monkeys, guinea-pigs, and rats were given intraperitoneal inoculations of Toxoplasma suspensions in normal saline. The inoculum consisted of $0.5 \mathrm{ml}$. of a 1 in 10 dilution of peritoneal fluid taken from mice with infections of three days duration. The animals were bled and sera obtained at periods as indicated in Table $I$.

Serum from an experimentally infected dog was received from the Royal Veterinary College, London, together with normal serum obtained from the same animal before infection.

One positive human serum was obtained from The Hospital for Sick Children, Great Ormond Street, and four others from the Bernhard-Nocht-Institut, Hamburg.

Normal human, monkey, guinea-pig, and rat sera were used as negative controls.

Complement fixation tests were now carried out with these sera which were used in serial dilutions of 1 in 5,1 in 10,1 in 20 . The antigen was used at a dilution to give four units of antibody per unit volume of the test $(0.11 \mathrm{ml}$.). Guinea-pig complement was used at 3 M.H.D. per unit volume, and the haemolytic system consisted of a $3 \%$ sheep cell suspension with 5 M.H.D. of haemolysin. The short fixation method was used of one hour for the initial incubation and 30 minutes secondary incubation at $37^{\circ} \mathrm{C}$. in the water-bath. All test sera were previously inactivated at $56^{\circ} \mathrm{C}$. for 30 minutes.

\section{Results}

Of the three adult guinea-pigs infected with Toxoplasma, two gave positive results on sera collected at periods from three weeks to six weeks,

TABLE I

COMPLEMENT-FIXATION REACTION (C.F.R.) ON TOXOPLASMA-IMMUNE SERA USING TOXOPLASMA AND SARCOCYSTIS ANTIGENS

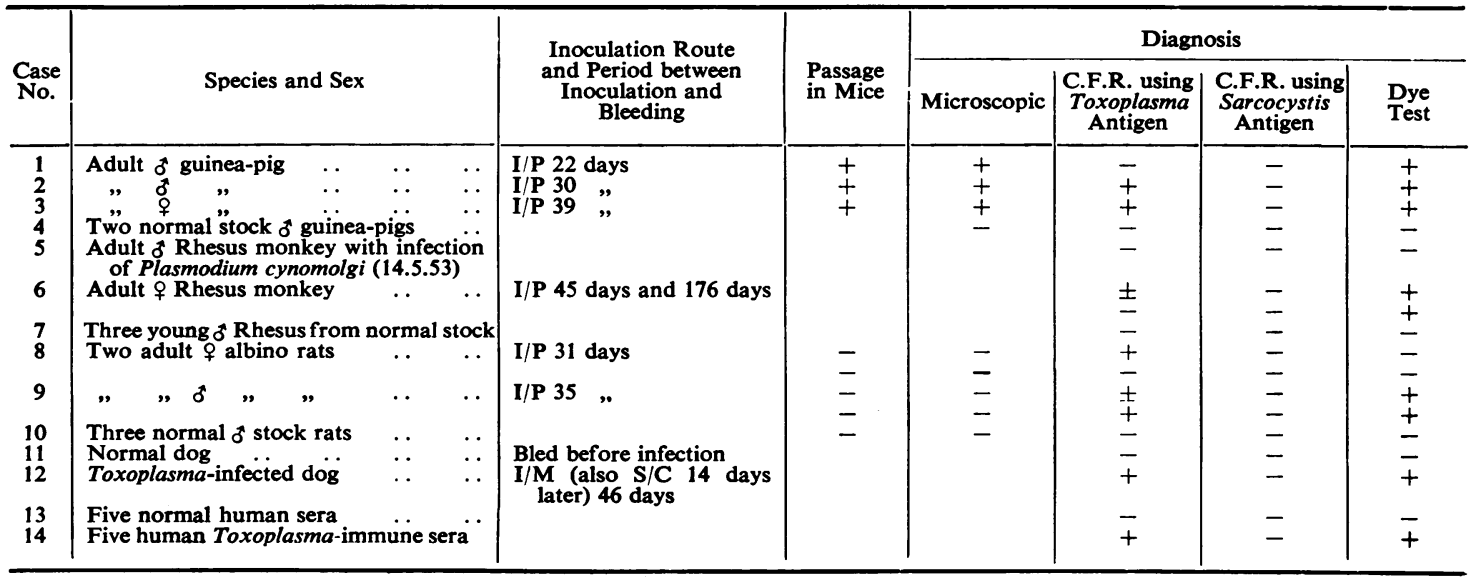


as shown in Table I. In all these animals toxoplasms were recovered by passage of tissues into laboratory white mice. The normal stock guineapigs returned negative tests.

The Rhesus monkey immune serum was collected six weeks and six months after the initial infection, and gave a strong positive reaction at six weeks and negative at six months. The sera from three normal stock monkeys and that from one monkey previously infected with Plasmodium cynomolgi were all negative.

The rats were bled one month following inoculation; two only gave a positive test, one was doubtful, and the fourth negative. In no case could the parasites be recovered by animal inoculation.

Serum from the dog taken before infection was negative, while that obtained after the infection was established was positive.

The human sera from The Hospital for Sick Children and from Hamburg were positive to the test; the "normal" sera were negative.

All the Toxoplasma-immune sera were tested using the dye test. The results shown in Table I indicate a good agreement except for one rat and one guinea-pig which developed cytoplasmmodifying antibody but remained negative to the complement-fixation reaction. In Case 6 both complement-fixation reaction and dye test were positive at six weeks, but the dye test only at six months.

Experiment B : Complement-fixation Reaction for Sarcosporidiosis.-An adult male guinea-pig was injected by the intraperitoneal route with $1.0 \mathrm{ml}$. of sarcocyst antigen. After one week the same dose was repeated and serum collected the week following. This serum was used as a positive control against which the antigen was titrated.

Normal guinea-pig serum was obtained for use as a negative control.

Forty-five sheep sera and tissues to be used in microscopic examination were collected from the abattoir.

Serum was obtained from a reported human case (Pugh, 1950).

Sera were taken from six young lambs 7-8 weeks old.

Antigen titration was performed by the typical " chess-board" method. The results obtained showed the most favourable dilution to be used in the test proper as 1 in 40 . The unit volume per tube was again $0.11 \mathrm{ml}$. ; the haemolytic system, a $3 \%$ suspension in saline of washed sheep cells with 5 M.H.D. of haemolytic serum prepared by using equal volumes of a $6 \%$ cell suspension and saline containing 10 M.H.D. haemolytic doses and incubated at $37^{\circ} \mathrm{C}$. for 30 minutes. The complement was used in the tests to give 3 M.H.D. per unit volume and the short fixation method. All sera were previously inactivated at: $56^{\circ} \mathrm{C}$. for 30 minutes and used in dilutions of 1 ins? 5,1 in 10 , and 1 in 20.

An identical experiment was carried out on the control positive serum, but using a 1 in 40 dilution ot the control antigen.

\section{Results}

The 45 sheep tested yielded 36 positive comple $\overrightarrow{0}$ ment-fixation reaction results. Examination of Tables II and III shows that of these 36 positive

TABLE II

COMPLEMENT-FIXATION REACTION (C.F.R.) ON SHEEPV SERA USING SARCOCYSTIS AND TOXOPLASMA ANTIGENS

\begin{tabular}{|c|c|c|c|c|c|}
\hline 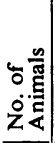 & Origin & Age & $\begin{array}{l}\text { Presence of } \\
\text { Sarcocystis }\end{array}$ & $\begin{array}{c}\text { No. } \\
\text { Positive } \\
\text { to C.F.R. } \\
\text { with } \\
\text { Sarcocystis } \\
\text { Antigen }\end{array}$ & $\begin{array}{c}\text { No. } \\
\text { Positive } \\
\text { to C.F.R } \\
\text { with } \\
\text { Toxoplasm } \\
\text { Antigen }\end{array}$ \\
\hline 20 & Devonshire & $3-5$ years & 16 positive & 12 & 0 \\
\hline 20 & Somerset & $3-4 \quad$ & 14 positive & 12 & 0 \\
\hline 5 & & Old cast & $\begin{array}{l}6 \text { negative } \\
5 \text { positive }\end{array}$ & $\begin{array}{l}2 \\
5\end{array}$ & $\begin{array}{l}1 \\
0\end{array}$ \\
\hline 6 & Experiment & 7-8 weeks & 6 negative & 0 & 0 \\
\hline
\end{tabular}

sheep, 31 possessed parasites, 26 of which wer禺 detected by microscopical means, and five showed? macroscopic oesophageal cysts. Five were sero $\overrightarrow{\overrightarrow{0}}$ logically positive in the absence of detectable parasites.

Nine sheep of the 45 gave a negative comples ment-fixation reaction. Of these nine, four pos sessed parasites shown by microscopical means:while the remaining five sheep were negative both. parasitologically and serologically.

Experiment C : Complement-fixation Reaction our Sheep and Experimental Sarcocystis-immune Sera. $\frac{0}{3}$ This was an exact repetition of Experiment B, but the Sarcocystis antigen was replaced by a Toxoplasm antigen.

\section{Results}

Among the 45 sheep tested as above in experi ment B, only No. 28 gave a definite positive result while No. 23 was doubtful. All other sera gave negative results as shown in Tables II and III.

Experiment D : Complement-fixation Reaction of? Toxoplasma-immune Sera.-This was an exact dupli= cation of Experiment A, but the Toxoplasma antigen had been replaced by a Sarcocystis one.

\section{Results}

All sera gave negative results as shown itr Table I. 
Experiment E : Sabin-Feldman Dye Test on Sheep Sera and Human Sarcocystis-immune and Guinea-pigimmune Serum. - The dye-test was carried out on the sera of sheep Nos. 21-40. Of these, 12 had been shown positive both to the complement-fixation reaction for sarcosporidiosis and to microscopic examination, four serologically only, two microscopically only, and two negative to both tests for sarcosporidia.

TABLE III

SHEEP SERA, A CASE OF SARCOSPORIDIOSIS, AND AN ARTIFICIALLY IMMUNIZED GUINEA-PIG TESTEDD BY THE COMPLEMENT-FIXATION REACTION USING SARCOCYSTIS AND TOXOPLASMA ANTIGENS AND THE DYE TEST

\begin{tabular}{|c|c|c|c|c|c|}
\hline 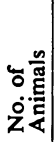 & Origin & $\begin{array}{l}\text { Presence of } \\
\text { Sarcocystis }\end{array}$ & $\begin{array}{c}\text { No. } \\
\text { Positive } \\
\text { to C.F.R. } \\
\text { with } \\
\text { Sarcocystis } \\
\text { Antigen }\end{array}$ & $\begin{array}{c}\text { No. } \\
\text { Positive } \\
\text { to C.F.R. } \\
\text { with } \\
\text { Toxoplasma } \\
\text { Antigen }\end{array}$ & $\begin{array}{l}\text { No. } \\
\text { Positive } \\
\text { to Dye } \\
\text { Test }\end{array}$ \\
\hline $\begin{array}{r}20 \\
5 \\
6 \\
1 \\
1\end{array}$ & $\begin{array}{l}\text { Somerset } \\
\text { Kent } \\
\text { Experiment } \\
\text { Human adult } \\
\text { Guinea-pig arti- } \\
\text { ficially inocu- } \\
\text { lated with Sar- } \\
\text { cocystis antigen }\end{array}$ & \begin{tabular}{|c|}
14 positive \\
6 negative \\
5 positive \\
6 negative \\
1 positive \\
-
\end{tabular} & $\begin{array}{r}12 \\
2 \\
5 \\
0 \\
1 \\
1\end{array}$ & $\begin{array}{l}0 \\
1 \\
0 \\
0 \\
0 \\
0\end{array}$ & $\begin{array}{l}7 \\
3 \\
1 \\
0 \\
0 \\
0\end{array}$ \\
\hline
\end{tabular}

The test was similarly carried out on the sheep 41-45 which possessed large oesophageal cysts, also on the six lambs which were negative to serological examination, and finally on the human serum which had proved positive to the complement-fixation reaction for sarcosporidiosis, and the control positive serum.

\section{Results}

Of the 20 sheep from Somerset, 14 were positive microscopically and six negative; of the 14 sheep positive microscopically, seven gave positive results. Among the six negative to microscopical examination, three gave positive results.

Of the five sheep from Kent with macroscopic cysts, only one gave a positive result. All the lambs as well as the human serum were negative. The correlation of all these results with those of other experiments is clearly indicated in Table III.

\section{Discussion}

In certain cases microscopical examination alone is not considered sufficient to differentiate between sarcosporidiosis and toxoplasmosis, therefore serological tests together with animal inoculations must form an important part in distinguishing between infections due to these parasites.

The reliability of the complement-fixation reaction and dye test for the diagnosis of Toxoplasma infections is shown, also that the complement fixation reaction is a reliable means of detecting sarcosporidial infections, and that this test is preferable to the dye test, as applied by Mühlpfordt, for detection of this infection in sheep. For example, the five sheep which had macroscopic evidence of infection gave positive complement-fixation reaction results, whereas only one positive and one doubtful were recorded when using the dye test. Again, among the 14 sheep showing microscopic evidence of Sarcosporidia 12 gave positive results for the complement-fixation reaction, while only seven did so for the dye test. Of the 31 sera tested by the dye test for sarcosporidiosis, only 14 agreed with the complement-fixation reaction findings ; on three occasions the dye test recorded a positive reaction on sera from sheep with undemonstrable parasites where the complementfixation reaction failed to do so, but, on the other hand, the dye test was negative 10 times when microscopical and complement-fixation reaction examinations were in agreement. Finally the human serum from the case that had been diagnosed as a sarcosporidial infection by examination of sections proved positive to the complementfixation reaction for sarcosporidiosis, negative to the complement-fixation reaction for toxoplasmosis, and negative also to the dye test.

An analysis of these results had led us to the opinion that, although the dye test gives positive results in some cases of sarcosporidiosis, it is not sufficiently reliable to be used as a means of diagnosing this infection in sheep. On the other hand, these non-specific reactions render the dye test equally unsuitable for the differential diagnosis of sarcosporidiosis and toxoplasmosis.

Experiments $C$ and $D$, however, indicate that, as far as the complement-fixation reaction is concerned, no demonstrable antigenic relationship exists between the two organisms Toxoplasma and Sarcocystis.

\section{Conclusions}

The dye test gave positive results with Toxoplasma sera ; also with some Sarcocystis sera.

The complement-fixation reaction using Toxoplasma antigen gave positive results with Toxoplasma sera but negative with Sarcocystis sera.

The complement-fixation reaction using Sarcocystis antigen gave positive results with Sarcocystis sera but negative with Toxoplasma sera.

We are deeply grateful to all who have helped us, in particular Professor P. C. C. Garnham, head of the Department of Parasitology, London School of Hygiene and Tropical Medicine, under whose supervision, guidance, and criticism this work was carried out; to Professor J. C. Cruickshank and Dr. F. Fulton of the Bacteriology Department, London School of Hygiene and Tropical Medicine, for tech- 
nical advice; to Mr. E. F. McCleary, M.R.C.V.S., D.V.S.M., Chief Veterinary Officer, Mr. R. G. Halcrow, M.R.C.V.S., Assistant Veterinary Officer, and Mr. H. T. Yelland, Assistant Meat Inspector, all of the Corporation of London Metropolitan Cattle Market, Islington, for supplying the materials from sheep ; to Dr. I. A. B. Cathie and Dr. J. A. Dudgeon of The Hospital for Sick Children, Great Ormond Street, London, for technical advice and provision of human Toxoplasma immune serum; and to Dr. A. Westphal of the Bernhard-Nocht-Institut, Hamburg, for the further provision of four positive human sera for Toxoplasma.

\section{REFERENCES}

Baraban, L., and Saint Remy, G. (1894). C.R. Soc. Biol., Paris, ser. 10, 1, 201.

Cathie, I. A. B., and Dudgeon, J. A. (1949). Journal of Clinical Pathology, 2, 259.

Darling, S. T. (1909). Arch. intern. Med., 3, 183.

(1919). J. Parasitology, 6, 98.

Kean, B. H., and Grocott, R. G. (1945). Amer. J. Path., 21, 467. Mühlpfordt, H. (1951). Z. Tropenmed. Parasit., 3, 205. (Abstract in Trop. Dis. Bull., 1952, 49, 322.)

Pugh, A. M. (1950). Trans. roy. Soc. trop. Med. Hyg., 44, 1.

Sabin, A. B., and Feldman, H. A. (1948). Science, 108, 660.

Warren, J., and Russ, S. B. (1948). Proc. Soc. exp. Biol., N.Y., 67, 85. - and Sabin, A. B. (1942). Ibid., 51, 11.

Wolf, A., Cowen, D., and Paige, B. (1939). Science, 89, 226. 